\title{
КОНФИКСАЛЬНЫЕ ГЛАГОЛЫ С СЕМАНТИКОЙ НЕГАТИВНЫХ ПОСЛЕДСТВИЙ ДЕЙСТВИЯ В СОВРЕМЕННОМ РУССКОМ ЯЗЫКЕ
}

В статье анализируются конфиксальные способы глагольного действия, выражающие семантику негативных последствий действия.

Представляется актуальным выяснить, связана ли общая идея негативных последствий действия с самой конфиксальной словообразовательной моделью; проанализировать взаимодействие в этих глаголах грамматической и лексической семантики; определить особенности аспектуальных ситуаций, в которых эти глаголы функционируют, их стилистические особенности; выявить те комплексы смыслов, носителями которых являются конфиксальные словообразовательные типы со значением негативных последствий

Установлено, что семантика негативных последствий действия может присутствовать в большей или меньшей степени, может быть выражена более явно, эксплицитно или более скрыто, имплицитно; может требовать поддержки определенного контекста или же выражаться самой глагольной формой и не нуждаться в специфическом контексте.

Определены семантические маркеры, сигнализирующие о наличии чрезмерной интенсивности или длительности действия, вызывающих негативные последствия действия.

Все способы действия со значением негативного результата действия представлены в виде функционально-семантического поля, определены центральные и периферийные компоненты поля в зависимости от степени эксплицитности выражения значения негативных последствий действия, а также интенсивности, чрезмерности, длительности, приводящих к этим послед- ствиям. Учитывается также регулярность и продуктивность типа.

Определено, за счет чего создается семантика негативных последствий действия и как она конкретизируется в каждом из описываемых способов действия.

Конфиксальные способы действия с семантикой негативных последствий действия исследуются с точки зрения функционально-стилистической, регулярности и продуктивности словообразовательного типа, видовой соотносительности.

Определяются причины преимущественной одновидовости указанных способов действия.

Выявлено, что анализируемые глаголы являются носителями нескольких ситуаций, комплекса смыслов, так как значение негативных последствий действия является следствием чрезмерности проявления действия, его интенсивности, длительности, иногда кратности. Производные глаголы являются компактным средством выражения сложной семантики, соотносимой с описательной конструкцией.

Делается вывод о том, что наличие в русском языке такого многообразия способов действия со значением негативных последствий действия, явившихся результатом чрезмерно интенсивного или длительного действия исходного глагола, говорит о значимости данного концепта (или нескольких концептов) для носителей русского языка, для русской языковой картины мира.

Ключевые слова: способы действия, интенсивность, длительность, чрезмерность действия, негативные последствия действия, количественная аспектуальность.

\section{CONFIXED VERBS WITH NEGATIVE SEMANTICS OF ACTION CONSEQUENCES IN MODERN RUSSIAN}

The confix ways of verbal action, which expresses negative semantics of action consequences, are under discussion in the article.

It seems relevant for the study to find out whether the general idea of the negative consequences of action is related to the confixed word-building model, to analyze the interaction of grammatical and lexical semantics of those type of verbs, to determine the features of aspectual situations, to reveal stylistic features of their functioning, to reveal the complexes of meanings expressed by confixed word-building types bearing the negative consequences semantics.

It is established that the negative semantics of action consequences can be presented explicitly or implicitly to a greater or lesser extent; the representation of the negative consequences of action can be expressed by the verb form or it can.require a certain context.

The semantic markers, that signal excessive intensity or duration of action, are identified.

All verbal actions, which denote the negative result, are presented as a functional and semantic field; the central and peripheral components of the field are determined depending on the degree of explicitness of the negative consequences of action, as well as its intensity, excessiveness and duration.. Regularity and efficiency of a verb type is also taken into account.

It is defined due to what factors the semantics of negative consequences of an action is created; it is specified in each specific action. 
The confix ways of verbal action with the semantics of the negative consequences of the action are investigated from the point of view of functionality and stylistics, regularity and productivity of derivational type, species correlation.

The reasons for the predominant uniformity of these ways of action are identified.

It is established that the verbs under analysis can cover multiple situations and convey the complex of meanings, since the semantics of the negative consequences of action is a consequence of excessive manifestation of an action, its intensity, duration and sometimes multiplicity. The derived verbs are a compact means of expressing

В современном русском языке имеется группа префиксально-постфиксальных и префиксальных способов действия (СД), выражающих семантику отрицательных последствий действия.

Сема негативного результата действия всегда сопряжена с чрезмерностью действия, его излишней интенсивностью, длительностью, иногда кратностью. Она может наличествовать в большей или меньшей степени, может быть выражена явно, эксплицитно или более скрыто, имплицитно; может требовать поддержки определенного контекста и без соответствующего контекста особо не актуализироваться или же выражаться самой глагольной формой и не нуждаться в специфическом контексте. Для того, чтобы определить степень присутствия в значении глагола семы негативных последствий действия (НПД), следует прежде всего определить маркеры, которые подтверждают наличие значения чрезмерной интенсивности или длительности действия и, как следствие, семантики отрицательных последствий действия. Определяя эти маркеры, мы исходим из того, что приставочный глагол - это синтагма, включающая два члена: мотивирующий глагол и формант. Мотивирующий глагол является отождествляющим членом синтагмы, а формант различающим членом [21, р. 32]. Определение в каждом конкретном случае детерминируемого члена словосочетания, отражающего семантику форманта, будет выявлять семантический маркер (или маркеры), который соответствует значению того или иного способа действия. Некоторые из этих маркеров применимы ко всем способам действия указанной группы, другие - только к некоторым. Это такие маркеры: «чрезмерно», "слишком», "совериенно», «совсем», «сильно», "очень», "долго», "вдоволь».

Все СД со значением негативного результата можно представить в виде функционально-семантического поля (ФСП), при этом определение СД в качестве центрального или периферийного компонента будет зависеть от того, какие маркеры соответствуют его семантике, насколько эксплицитно выражено значение НПД, а также интенсивности, чрезмерности, длительности, приводящих к этим последствиям. Необходимо, на наш взгляд, также учитывать регулярность и продуктивность типа. Более обширный языковой материал позволил нам внести некоторые complex semantics, which correlates with the descriptive construction.

It is concluded that the presence in the Russian language of such a variety of ways of action with the meaning of the negative consequences of action, which were the result of excessively intense or prolonged action of the original verb, indicates the importance of a certain concept (or several concepts) for Russian speakers and for the Russian language picture of the world.

Key words: ways of action, intensity, duration, excessiveness of action, negative result, consequences of action, quantitative aspectuality.

коррективы в структуру ФСП негативных последствий действия, определенную в более ранних работах, в частности, мы несколько изменили соотношение компонентов центра и периферии данного поля [ср. 7, p. 77].

Применяя эти критерии, мы отнесли к центру поля НПД следующие конфиксальные СД, эксплицитно выражающие значение отрицательных последствий действия и являющиеся очень регулярными и, как правило, продуктивными: чрезмерно-кратный (терминология М. А. Шелякина [21]) с конфиксом из-...-ся (измучиться), финально-отрицательный с конфиксом до-...-ся (догуляться (до простуды), чрезмерно-длительный с конфиксом за-...-ся (забегаться); а также префиксальные СД: чрезмерно-продолжительный с приставкой за- (зачитать (до дыр), сверхнормативно-длительный с приставкой пере- (передержать).

Несколько дальше, но все же в центре, будут расположены, с нашей точки зрения, такие СД: чрезмерно-интенсивный с конфиксом $y$-...-ся (убегаться), префиксальный словообразовательный тип с приставкой $y$ - со значением отрицательных последствий действия (укатать), тотальный способ действия с приставкой из- (ucсуиuть). В семантике чрезмерно-интенсивного СД и префиксального типа с приставкой у-сема «отрицательные последствия действия» выражена очень отчетливо, эксплицитно, однако эти типы непродуктивны. Тотальный СД является очень регулярным и продуктивным, однако сема негативного результата не обязательно присутствует в его семантике, хотя и возникает часто как следствие интенсивности, рассредоточенного воздействия действия на объект или субъект.

Наконец, скорее к периферии можно отнести финитивный СД с приставкой до- (до-лечить), сативный СД с конфиксом на-...-ся (напиться (до потери сознания), конфиксальный тип с формантом вы-..-ся (выбегаться), чрезмерно-нормативный СД с приставкой пере- (перемерзнуть), а также префиксальный и конфиксальный словообразовательные типы с приставкой об- (например, объесть, обноситься).

В семантике, например, сативного СД негативный результат обязательно не предполагается, основное значение сативного СД - это выражение полного удовлетворения действием. 
Однако состояние полного удовлетворения легко переходит в пресыщенность действием, которая может рассматриваться уже как НПД. Чрезмерно-нормативный СД с приставкой пере- является непродуктивным словообразовательным типом, а финитивный СД, а также словообразовательные типы с приставкой об- и конфиксом об-...-ся не предполагают обязательного наличия отрицательного результата действия, хотя это значение может возникать в некоторых из этих глаголов за счет лексического значения и контекста

Следует конкретизировать и само значение отрицательных последствий действия. В разных СД этот негативный результат имеет свои оттенки. Это может быть причинение какого-то вреда субъекту или объекту действия; изменение состояния субъекта или объекта, вызванное действием (возникновение состояния утомления чрезмерного увлечения, исчерпанности, пресыщенности действием); неспособность дальнейшего продолжения действия вследствие крайней степени усталости, бессилия; исчерпанность субъекта или объекта; уничтожение объекта.

Таким образом, например, в глаголе чрезмерно-продолжительного СД зачитать (до дыр) или в глаголе чрезмерно-кратного СД изнервничаться отрицательный результат является следствием чрезмерности, повторяемости или длительности действия и проявляется как состояние негодности, утомления, исчерпанности. В глаголе накупаться (до (утомления) актуальна «чрезмерность» действия, являющаяся результатом слишком длительного и интенсивного его характера, и отрицательный результат проявляется как пресыщенность действием и т.д.

Многие из интересующих нас СД являются конфиксальными. В конфиксальных, то есть префиксально-постфиксальных глаголах, степень интенсивности действия повышается за счет того, что действие в большей степени сосредоточено на субъекте, что вызывает излишнюю активность субъекта. Как известно, конфиксальный способ не является исконно русским способом словообразования, он возник как самостоятельный способ в период разрушения семантического синкретизма языковых единиц, в результате чего преодолевалась прежняя нерасчлененность значений древнерусского слова (категориального, лексического, словообразовательного) и укреплялась языковая парадигматика.

Причины и пути возникновения конфиксации как самостоятельного способа словообразования интересовали, например, В. М. Маркова, Г. А. Николаева $[17,19]$, которые оценивали конфиксы как самостоятельные морфемы [19]

Довольно распространенным является мнение, что конфиксация возникла в результате переразложения в структуре глаголов [например 20 , 4]. В более ранних своих работах мы, разделяя приведенное мнение, вместе с тем дополняли его уточнением, что другим способом возникновения конфиксации является трансформация первоначально приставочного способа словообразования в префиксально-постфиксальный
Подтверждением этому является то, что префиксально-постфиксальные и префиксальные глаголы с определенным значением сосуществуют в течение значительного временного периода $[8$, p. 189-190].

Таким образом, история префиксально-постфиксальных способов действия глагола позволят проследить процесс возникновения и становления конфиксального способа словообразования, когда не характерные ранее для русского языка дискретные форманты стали функционировать как единое морфологическое целое в словообразовательном акте [8, p. 227-228]

Рассмотрим более пристально те коноиисальные словообразовательные типы, которые наиболее ярко, эксплицитно выражают семантику НПД и отнесены нами к центру поля НПД (чрезмерно-кратный с конфиксом из- ... -ся, финально-отрицательный с конфиксом до- ... -ся, чрезмерно-длительный с конфиксом за- ... -ся, чрезмерно-интенсивного СД с консриксом $y-\ldots$ - - я).

Чрезмерно-кратный СД с формантом из-...-ся является одним из самых регулярных префиксально-постфиксальных СД. В. В. Лопатин и И. С. Улуханов характеризуют данный тип так: «интенсивно, длительно или часто совершая действие, названное мотивирующим глаголом, дойти до какого-л. состояния (обычно утомления, негодности, исчерпанности), приобрести или утратить определенные качества, способности или привычки» [16, р. 93]. Словообразовательный тип, соответствующий данному СД, особенно продуктивен в разговорной речи и просторечии. В нашем материале эти глаголы представлены очень широко. Отрицательные последствия действия часто описаны в контексте, например

«Дело шло ... о том, как он маялся и горе мыкал здесь, в Петербурге, как бесплодно долгое время места искал, прожился, исхарчился, жил чуть не на улице, ел черствый хлеб и запивал его слезами своими...» [12].

Крайняя, чрезмерная степень проявления действия может актуализироваться обстоятельствами (вконеи, весь, здорово, очень, совсем, до последней худобы, до заморённого подростка и под.):

«Клубилась пыль вокруг этого мохнатенького, всё время жужжащего какой-нибудь мотив, до последней худобы износившегося существа» [2]

«...Рюкзак этот, сталинский подарок, чтоб ему в лоскутья изорваться, висел на ней до самой земли» [1].

«О люди! Все иззавидовались, черти. Что такое, не могут люди спокойно выносить, когда кому-нибудь повезет» [22]

В имеющемся языковом материале соотношение глаголов данного СД в произведениях Ф. М. Достоевского и В. Шукшина - один к десяти, что обусловлено преимущественно разговорной или просторечной стилистической окраской глаголов этого типа (например, издергаться, измотаться, изозлиться, изождаться, испаскудиться, испсиховаться, исхарчиться, исхлестаться 
и т.д.), реже это стилистически нейтральные глаголы (измаяться, измучиться, изнервничаться, исписаться).

Глаголы чрезмерно-кратного СД представлены преимущественно в совершенном виде, иногда встречаются имперфективные формы глаголов со значением кратности действия, например:

«Правда и то, что и сами эти господа таланты средней руки, на склоне почтенных лет своих, обыкновенно самым жалким образом у нас исписываются, совсем даже и не замечая того» [10].

В чрезмерно-кратном СД сема НПД выражена очень отчетливо и сопряжена с другими семами: интенсивности, длительности, часто кратности. Отрицательные последствия действия проявляются как негативное состояние субъекта (чрезмерной усталости, исчерпанности и т.д.) в результате интенсивного, кратного или длительного совершения действия, названного мотивирующим глаголом.

Семантика НПД в глаголах чрезмерно-кратного СД выражена эксплицитно, явно, контекст не является необходимым элементом для актуализации этой семантики, хотя часто иллюстрирует конкретные проявления НПД. Данный словообразовательный тип является очень регулярным и продуктивным.

Глаголы чрезмерно-длительного СД с конфиксом за-...-ся определяются так: «довести себя до какого-л. состояния (увлечения, утомления) в результате интенсивного или длительного (иногда чрезмерно интенсивного или длительного) действия, названного мотивирующим глаголом; целиком погрузиться в это действие (неперех.) (за-бегать-ся (разг.) «утомиться от длительного бега", за-танцевать-ся (разг.) "увлечься танцами; устать от долгих танцев", за-беседовать-ся (разг.), за-врать-ся (разг.), за-гулять-ся (разг.), за-есть-ся (прост.), за-ждать-ся (разг), за-играться, за-работать-ся (разг.), за-смотреть-ся, за-слушать-ся, за-хлопотать-ся (разг.)", отмечается продуктивность типа [16, р. 83].

Эти глаголы также представлены в нашем материале очень широко, они характерны как для произведений, в которых преобладает разговорная речь (В. М. Шукшина, М. М. Зощенко), так и для произведений классической русской литературы (Ф. М. Достоевского, Н. В. Гоголя, И. А. Бунина, Г. Газданова и др.). Характерными контекстами функционирования глаголов чрезмерно-длительного СД являются конструкции типа: до такой степени, что...; до того, что.. [5, p. 217]. НПД часто конкретизированы в контексте (предложно-падежными конструкциями, обстоятельствами степени, кратким или более развернутым описанием конкретного негативного результата действия). Например:

«Гораздо замечательнее был наряд его: никакими средствами и стараньями нельзя бы докопаться, из чего состряпан был его халат: рукава и верхние полы до того засалились и залоснились, что походили на юфтьь, какая идет на сапоги...» [9].

«-А заелся ваш секретарь-то! - сказал лысый, глядя прямо перед собой. - Ох, заелся! - Он заза-за... это... зашился, а не заелся» [26].
«Парень вон у Гилевых... Игнаху-то Гилева помнишь? Вот сын его, Витька, - зачитался: $m и$ хое помешательство» [26].

Имперфективные формы возможны для глаголов чрезмерно-длительного СД:

«Сцепились. Ты, Геночка, не зачитался случаем? Шибко уж языкастый да кулакастый стал. Смотри, а то, бывает, до дури зачитываются с ума сходят» [24].

В глаголах чрезмерно-длительного СД с конфиксом за-...-ся НПД представлены как чрезмерное погружение в действие, состояние увлечения, утомления субъекта в результате интенсивного или длительного (иногда чрезмерно интенсивного или длительного) действия, названного мотивирующим глаголом

Сема негативного результата действия наличествует в глаголах с конфиксом до-...-ся, относящимся к финально-отрицательному СД и указывающим на чрезмерность проявления действия, вызывающую отрицательные для субъекта последствия: докричаться до хрипоты, доиграться до ссоры, догуляться до простуды и под. [21, р. 81]. В. В. Лопатин и И. С. Улуханов отмечают характерность данного типа для разговорной речи и просторечия (до-гулять-ся, до-курить-ся, до-петься, до-сидеть-ся, до-слушать-ся, до-спать-ся, доспорить-ся, до-читать-ся - все разг.) [16, р. 75].

Глаголы финально-отрицательного СД обладают способностью образовываться от любых непредельно-непереходных глаголов [5, р. 216], например:

«Виталя Кукин понимал: над ним глумятся и о, ужас! - вроде бы глумятся и над передовой идеологией!.. Мы, однако, дошутились бы: часть энкавэдэшная, в основе своей стукаческая» [2].

«Допился он и догулялся до крайности. Раненный в локоть, он боль от раны и всякую боль, видать, привык подавлять вином, да еще и по девкам лазил - и руку ему отняли, даже не отняли, выщелочили и вылущили, как там, по-медицински, из самого плеча» [1].

«Отсеяли меня из эшелона, под конвоем увели в комендатуру - довоевался! Допрыеался!) [1].

Глаголы финально-отрицательныго СД редко представлены в несовершенном виде, например:

«- Я сам выпиваю очень умеренно. У меня есть сосед; инженер-конструктор... Допивается до того, что опохмелиться утром рубля нет» [28].

Поскольку глаголы финально-отрицательного СД очень экспрессивны, они в большей степени характерны для разговорной речи и соответственно для произведений, в которых разговорная речь преобладает [ср. 7, р. 76]. В произведениях В. Шукшина глаголы финально-отрицательного СД очень часты, причем характерно для этого писателя то, что конкретные проявления негативного результата действия часто описываются в контексте и без такого специфического контекста некоторые глаголы (дождаться, додуматься и под.) можно было бы отнести к длительно-усилительному СД, выражающему только интенсивность и длительность действия. Тот факт, что одни и те же глаголы с формантом до-...-ся могут высту- 
пать в значении длительно-усилительного или финально-отрицательного СД, свидетельствует об отсутствии четких границ между этими двумя СД, а также о большой роли контекста в создании семантики НПД [5, р. 217]. Например, приведенные ниже глаголы додуматься, дождаться могут выражать семантику длительно-усилительного СД, однако в данном контексте они имеют скорее значение финально-отрицательного СД благодаря контексту:

«- То-то, брат, вот этакая валаамова ослица думает, думает, да и черт знает про себя там до чего додумается. - Мыслей накопит, - усмехнулся Иван...» [11].

«- Колька сам подивился - будто не он сказал эти страшные слова, а кто-то другой, сказал обдуманно. - Дождалась ты своей участи... Не хотела жить на белом свете? Подыхай» [25].

Глаголы фринально-отрицательного СД часто встречаются в синтаксических конструкциях типа до mozo, что...

«Как можно докатиться до того, чтобы ни одного вала в запасе не было?» [26]

Это может быть развернутая синтаксическая конструкция, описывающая негативный результат действия:

«Привяжут человека к столбу, выбреют макушку и капают на эту плешину по капле холодной воды - никто почесть не выдерживал. Вот додумались! Мы тоже удивлялись, а некоторые совсем не верили» [27].

«В самый разаар уборочной в колхозе «Заря коммунизма» выили из строя две автомашины полетели коленчатые валы. Колхозный механик Сеня Громов, сухой маленький человек, налетел на шоферов соколом. - До-дд-доигрались?! Сеня заикался. - До-д-допрыгались?!» [26].

Глаголы с конфиксом до-...-ся часто выражают угрозу или обещание негативных последствий, например:

«- Дождешься ты, Серега: подвернется какой-нибудь вьюн с гитарой - только и видел свою Леночку" [23].

Вместе с тем нельзя утверждать, что семантика негативных последствий действия создается только благодаря контексту и ситуации, она актуализируется и за счет употребления стилистически сниженной лексики, составляющей мотивирующую базу этого СД (докатиться, допрыгаться, докорячиться, дофорситься и под.). Наконец, очень важно, что сама семантика словообразовательной модели до-...-ся участвует в формировании значения НПД, которое поэтому так легко развивается в глаголах с этим конфиксом.

Таким образом, при функционировании глаголов финально-отрицательного СД семантика НПД может присутствовать в большей или меньшей степени, и проявляется она как возникновение негативно оцениваемого состояния субъекта (возникновение состояния увлечения, утомления негодности, исчерпанности), негативное развитие событий, негативная ситуация как следствие действий субъекта.
Глаголы чрезмерно-интенсивного СД с формантом $y$ - ... -ся выражают крайнюю степень продолжительности и интенсивности действия, вызывающую усталость субъекта, невозможность дальнейшего продолжения действия [21, р. 81].

В. В. Лопатин, И. С. Улуханов определяют данный словообразовательный тип следующим образом: «довести себя, дойти до какого-л. состояния (преимущ. до крайней усталости, бессилия, исчерпанности) с помощью действия, названного мотивирующим глаголом (непереходным) (у-бегать-ся “утомиться от длительного бега), у-ездить-ся (прост.), у-прыгать-ся (разг.), у-ходить-ся (прост.), у-пить-ся (прост.) «напиться до полного насыщения или допьяна», у-лежать-ся (прост.) «после длительного лежания стать готовым к использованию (о недозрелых фруктах, овощах)», у-стоять-ся ..., у-бродить-ся (прост.) ... Продуктивен в разг. речи и прост.» [16, р. 233]. Характерными особенностями этого СД являются его стилистическая маркированность (эти глаголы имеют обычно разговорную или просторечную окраску (например, упрыгаться, убегаться, упахаться и др.), представленность только в совершенном виде, а так же и то, что данный тип не является регулярным.

Анна А. Зализняк, например, объясняет стилистическую маркированность приставки $y$ - ее устареванием, вызвавшим различные рефлексы: одни глаголы с этой приставкой приобрели архаическую окраску, а другие - просторечно-разговорную [14].

В произведенияX писателей XIX - нач. XX века (Ф. М. Достоевского, Н. В. Гоголя, И. А. Бунина, А. Н. Толстого, А. И. Куприна) глаголы с конфиксом у-...-ся встречаются очень ограниченно, например:

«А вот поймайте-ка его, подите, теперь! вскрикнул он, злорадно подзадоривая Заметова... Упрыгаетесь! Вот ведь что у вас главное: тратит ли человек деньги или нет?» [13].

«И глагола ему: всяк человек прежде доброе вино полагает, и егда упиются, тогда хуждшее: ты же соблюл еси доброе вино доселе» [11].

В произведениях, в которых преобладает разговорная речь (например, В. Шукшина, И. Э. Бабеля, М. М. Зощенко, В. Астафьева и др.), эти глаголы встречаются значительно чаще, например:

«Вот тебе шинель Вадима Петровича, Вовкино одеялко и половичок. Стелись, где тебе удобней. Командир мой уже готов, и я умыкалась» [2].

«За околицей совхозного селения, заметно обнажившегося - кони примяли и выели заросли, догадался я, - Вадим Петрович разохался: уездился, дескать, с непривычки, даже спина «села», - пожал мне руку и отправился в обратный путь» [2].

Глаголы чрезмерно-интенсивного СД в несовершенном виде возможны в исключительных случаях, например:

«И отрабатывали, и урабатывались, выходных и праздных часов не знали ни тот, ни другой» [3]

Таким образом, семантика НПД создается в исследуемых глаголах за счет нескольких факторов. Во-первых, в процессе словообразования происходит взаимодействие аффикса и мотивиру- 
ющей основы, которое подчинено семантическим, стилистическим, структурно-словообразовательным и формальным закономерностям [7, р. 77].

Во-вторых, в формировании значения НПД у исследуемых префиксально-постфиксальных глаголов участвует и семантика самой словообразовательной модели, а не только семантика его составляющих (производящей основы и форманта) [7, р. 77]

Наконец, при оценке словообразовательных единиц, каковыми являются и рассматриваемые нами глаголы, большую роль играет не только внутренний контекст (мотивирующий глагол), но и внешний контекст, и это особенно актуально для глагола.

Интересующие нас СД очень экспрессивны, стилистически окрашены, что обусловливает их преимущественное функционирование в разговорной речи и просторечии [5, p. $218 ; 6$, p. 60]. Почти все словообразовательные типы, соответствующие этим СД, являются регулярными и продуктивными, кроме чрезмерно-интенсивного с конфиксом $y-\ldots-с я$. Они чаще являются одновидовыми - совершенного вида, хотя у некоторых из них возможны соотносительные формы несовершенного вида со значением повторяемости действия. Предпочтительная одновидовость этих глаголов объясняется тем, что семантика чрезмерной интенсивности действия, крайней степени проявления действия, вызывающей НПД, в большей степени совместима с совершенным видом, который сосредоточивает внимание не на процессе протекания, а на факте совершения действия [5, p. 218; 6, p. 60]. Вторым фактором, препятствующим образованию имперфективных форм, является эмоционально-экспрессивная окраска глаголов. Об этом писал и Ю. С. Маслов, подчеркивая, что любая стилистически окра- шенная передача действия «сосредоточивает внимание на факте как таковом, на факте в его неразложимой, не поддающейся развертыванию целостности» $[18$, р. 202]

В последнее время единицы словообразовательной системы все чаще анализируются в аспекте когнитивной парадигмы языкознания, позволяющей глубже понять сущность словообразовательных значений и когнитивных структур, соответствующих им, обнаружить особенности категоризации мира словообразовательными средствами. В формировании языковой картины мира все большую роль играют средства вторичной номинации, т.е. производные слова. Словообразовательная система в русском языке быстро реагирует на меняющиеся коммуникативные потребности общества и создает производные слова вместо громоздких описательных конструкций, что вполне соотносится с тенденцией к экономии языковых средств.

Производные глаголы имеют ряд характерных признаков: как правило, они являются носителями нескольких ситуаций, комплекса смыслов, т.е. могут указывать на само действие, на субъекта $и$ объекта этого действия, характер осуществления действия (интенсивное, длительное, многократное и т.д.), последствия действия (в том числе негативные). Производные глаголы являются компактным средством выражения сложной семантики, соотносимой с описательной конструкцией.

Наличие в русском языке такого многообразия СД со значением негативных последствий действия, явившихся результатом чрезмерно интенсивного или длительного действия исходного глагола, говорит о значимости данного концепта (или нескольких концептов) для носителей русского языка, для русской языковой картины мира $[7$, p. 77$]$.

\section{Литература}

1. Астафьев В. Веселый солдат (1987-1997) // Новый Мир, 1998 // Национальный корпус русского языка URL: http:// www. ruscorpora.ru. (Дата обращения: 16.08.2018).

2. Астафьев В. Обертон (1995-1996) // Национальный корпус русского языка URL: http://www. ruscorpora.ru. (Дата обращения: 22.07.2018).

3. Астафьев В. Пролетный гусь (2000) // Национальный корпус русского языка URL: http://www. ruscorpora.ru. (Дата обращения: 05.07.2018).

4. Бубекова Л. Б. Конфиксальные глаголы и их синтаксические отношения в русском языке: автореф. дис. ... канд. филол. наук. Казань, 2004. 18 с.

5. Ван Ц. Глаголы со значением отрицательных последствий действия в современном русском языке: системный и функциональный аспекты // Гуманитарные и юридические исследования. 2017. Вып. 3. С. 21 4-221.

6. Ван Ц. Способы гпагольного действия со значением негативного результата в современном русском языке // Вестник Нижегородского лингвистического университета им. Н. А. Добролюбова. 2017. Вып. 40. С. 52-62.

7. Ван Ц., Годизова 3. И. Способы глагольного действия с семантикой отрицательных следствий действия в методике преподавания современного русского языка // Вестник СОГУ. 2017. Вып. 4. С. 71-77.

8. Годизова 3. И. Становление семантической категории интенсивности в русском языке XI-XVII вв. Владикавказ: Изд-во СОГУ, 2018. 346 с.

9. Гоголь Н. В. Мертвые души (1842) // Национальный корпус русского языка URL: http://www. ruscorpora.ru. (Дата обращения: 08.05.2018, 10.05.2018).

10. Достоевский Ф. М. Бесы (1871-1872) // Национальный корпус русского языка URL: http://www. ruscorpora.ru (Дата обращения: 08.05.2018, 10.05.2018).

11. Достоевский Ф. М. Братья Карамазовы (1880) // Национальный корпус русского языка // URL: http://www. ruscorpora.ru. (Дата обращения: 10.04.2018, 14.04.2018).

12. Достоевский Ф. М. Двойник (1846) // Национальный корпус русского языка URL: http://www. ruscorpora.ru. (Дата обращения: 19.04.2018, 22.04.2018). 
13. Достоевский Ф. М. Преступление и наказание (1866) // Национальный корпус русского языка URL: http://www. ruscorpora.ru. (Дата обращения: 17.05.2018, 18.05.2018).

14. Зализняк Анна А. Семантическая деривация в значении русской приставки у- // Глагольные префиксы и префиксальные глаголы. 2001. Т.5. №1. С. 69-79.

15. Колесов В. В. Русская ментальность в языке и тексте. СПб.: Петербургское Востоковедение, 2007. 624 с.

16. Лопатин В. В., Улуханов И. С. Словарь словообразовательных аффиксов современного русского языка. М.: ИЦ «Азбуковник», 2016. 812 c.

17. Марков В. М. Замечания о конфиксации в современном русском языке // Jezyk Rosyjski. Warszawa, 1968. №3. C. 7-12.

18. Маслов Ю. С. Глагольный вид в современном болгарском литературном языке // Вопросы грамматики болгарского литературного языка. М.: [б.и.], 1959. С. 157-312.

19. Николаев Г. А. Русское историческое словообразование: Теоретические проблемы. М.: «Книжный дом «ЛИБРОKOM», 2009. $177 \mathrm{c}$.

20. Сигалов П. С. Задачи и возможности сопоставительного и сравнительно-исторического изучения способов действия славянского глагола // Вопросы сопоставительной аспектологии. Л.: [б.и.], 1978. С. 44-56.

21. Теория функциональной грамматики. Введение. Аспектуальность. Временная локализованность. Таксис. М. УРСС Эдиториал, 2003. 352 с.

22. Шукшин В. Беспалый (1972) // Национальный корпус русского языка URL: http://www. ruscorpora.ru. (Дата обращения: 16.07.2018).

23. Шукшин В. Воскресная тоска (1958) // Национальный корпус русского языка URL: http://www. ruscorpora.ru. (Дата обращения: 16.07.2018).

24. Шукшин В. Гена пройдисвет (1970-1974) // Национальный корпус русского языка URL: http://www. ruscorpora.ru. (Дата обращения: 16.07.2018).

25. Шукшин В. Жена мужа в Париж провожала (1970-1974) // Национальный корпус русского языка URL: http://www. ruscorpora.ru. (Дата обращения: 18.07.2018).

26. Шукшин В. Коленчатые валы (1958) // Национальный корпус русского языка URL: http://www. ruscorpora.ru. (Дата обращения: 18.07.2018).

27. Шукшин В. Пост скриптум (1970-1974) // Национальный корпус русского языка URL: http://www. ruscorpora.ru. (Дата обращения: 18.07.2018).

28. Шукшин В. Чередниченко и цирк (1970-1974) // Национальный корпус русского языка URL: http://www. ruscorpora ru. (Дата обращения: 18.07.2018).

\section{References}

1. Astafiev V. Veselyiy soldat (Cheerful Soldier) (1987-1997) // New World, 1998// National corpus of the Russian language URL: http://www. ruscorpora.ru. (Accessed: 16.08.2018). (In Russian).

2. Astafiev V. Oberton (Overtone) (1995-1996) // National corpus of Russian language URL: http://www ruscorpora.ru (Accessed: 22.07.2018). (In Russian).

3. Astafiev V. Proletnyiy gus (Flying Goose) (2000) // National corpus of Russian language URL: http://www ruscorpora. ru. (Accessed: 05.07.2018). (In Russian).

4. Boobekova L. B. Konfiksalnye glagoly $i$ ih sintaksicheskie otnosheniya v russkom yazyke (Confixed Verbs and Their Syntactic Relations in the Russian Language): abstract of thesis. Kazan, 2004. 18 p. (In Russian).

5. Wang Q. Glagoly so znacheniem otricatel'nyh posledstvij dejstviya v sovremennom russkom yazyke: sistemnyj i funkcional'nyj aspekty (Verbs Meaning Negative Attending Circumstances in the Modern Russian Language: Systematic and Functional Aspects) // Gumanitarnye i yuridicheskie issledovaniya. 2017. No. 3. P. 214-221. (In Russian).

6. Wang Q. Sposoby glagolnogo dejstviya so znacheniem negativnogo rezultata $v$ sovremennom russkom yazyke (Modes of Verbal Action with the Meaning of Negative Result in the Modern Russian Language) // Vestnik Nizhegorodskogo lingvisticheskogo universiteta im. N.A. Dobrolyubova. 2017. Issue.40. P. 52-62. (In Russian).

7. Wang Q., Godizova Z. I. Sposoby glagolnogo dejstviya s semantikoj otricatelnyh sledstvij dejstviya $v$ metodike prepodavaniya sovremennogo russkogo yazyka (Types of Verb Action Meaning Negative Result in Methods of Teaching Russian) // Vestnik SOGU. 2017. Issue. 4. P. 71-77. (In Russian).

8. Godizova Z. I. Stanovlenie semanticheskoj kategorii intensivnosti v russkom yazyke XI-XVII vV. (Formation of the Semantic Category of Intensity in the Russian Language of XI-XVII Centuries). Vladikavkaz: Publishing house of SOGU, 2018. 346 p. (In Russian).

9. Gogol N. V. Mertvyie dushi (Dead Souls) (1842) // National corpus of Russian URL: http://www ruscorpora.ru. (Accessed: 08.05.2018, 10.05.2018). (In Russian).

10. Dostoevskiy F. M. Besyi (Demons) (1871-1872)// Natsionalnyiy korpus russkogo yazyika URL: http://www. ruscorpora. ru. scorpora-intro.html (Accessed: 08.05.2018, 10.05.2018). (In Russian).

11. Dostoevskiy F. M. Bratya Karamazovyi (The Karamazov Brothers) (1880) // Natsionalnyiy korpus russkogo yazyika URL: http://www. ruscorpora.ru. scorpora-intro.html (Accessed: 10.04.2018, 14.04.2018). (In Russian).

12. Dostoevsky F. M. Dvoynik (The Double) (1846) // National corpus of the Russian language URL: http://www.ruscorpora. ru. (Accessed: 19.04.2018, 22.04.2018). (In Russian).

13. Dostoevskiy F. M. Prestuplenie i nakazanie (Crime and Punishment) (1866) // Natsionalnyiy korpus russkogo yazyika URL: http://www. ruscorpora.ru. scorpora-intro.html (Accessed: 17.05.2018, 18.05.2018). (In Russian).

14. Zaliznyak Anna A. Semanticheskaya derivaciya v znachenii russkoj pristavki u- (Semantic Derivation in the Meaning of Russian Prefixes u-) // Verbal prefixes and prefixes. 2001. Vol.5. No.1. P. 69-79. (In Russian).

15. Kolesov V. V. Russkaya mentalnost v yazyke i tekste (Russian Mentality in Language and Text). St.Petersburg: Petersburg Oriental Studies, 2007. 624 p. (In Russian). 
16. Lopatin V. V., Uluhanov I. S. Slovar slovoobrazovatelnyh affiksov sovremennogo russkogo yazyka (Dictionary of Wordformation Affixes of the Modern Russian Language). Moscow: IC «Azbukovnik», 2016. 812 p. (In Russian).

17. Markov V. M. Zamechaniya o konfiksacii v sovremennom russkom yazyke (Observations on Confiserie in the Modern Russian Language) // Jezyk Rosyjski. Warszawa, 1968. No. 3. P. 7-12. (In Russian).

18. Maslov Y. S. Glagolnyj vid v sovremennom bolgarskom literaturnom yazyke (Verbal Form in the Contemporary Bulgarian Literary Language) // Questions of grammar of Bulgarian literary language. Moscow, 1959. P. 157-312. (In Russian).

19. Nikolaev G. A. Russkoe istoricheskoe slovoobrazovanie: Teoreticheskie problemy (Russian Historical Word-formation: Theoretical Problems). Moscow: «Book house «LIBROCOM», 2009. 177 p. (In Russian).

20. Sigalov P. C. Zadachi i vozmozhnosti sopostavitelnogo i sravnitelno-istoricheskogo izucheniya sposobov dejstviya slavyanskogo glagola (Challenges and Opportunities for Comparative and Comparative-historical Study of the Modes of Action of the Slavic Verb) // The issues of the comparative Aspectology. Leningrad, 1978. P. 44-56. (In Russian).

21. Teoriya funkcionalnoj grammatiki. Vvedenie. Aspektualnost. Vremennaya lokalizovannost. Taksis (Theory of Functional Grammar. Introduction. Aspectuality. Temporal localization. Taxis). Moscow: URSS Ehditorial, 2003. 352 p. (In Russian).

22. Shukshin V. Bespalyj (Fingerless) (1972) // National corpus of Russian language URL: http://www ruscorpora.ru. (Accessed: 16.07.2018). (In Russian).

23. Shukshin V. Voskresnaya toska (Sunday Melancholy) (1958) // National corpus of Russian URL: http://www ruscorpora. ru. (Accessed: 16.07.2018). (In Russian).

24. Shukshin V. Gena proydisvet (Gena Pass-Through-The-Light) (1970-1974) // National corpus of Russian language URL: http://www ruscorpora.ru. (Accessed: 16.07.2018). (In Russian).

25. Shukshin V. Zhena muzha v Parizh provozhala (The Wife Escorted Her Husband to Paris) (1970-1974) // national corpus of the Russian language URL: http://www. ruscorpora.ru. (Accessed: 18.07.2018). (In Russian).

26. Shukshin V. Kolenchatyie valyi (Crankshafts) (1958) // National corpus of the Russian language URL: http://Www ruscorpora.ru. (Accessed: 18.07.2018). (In Russian).

27. Shukshin V. Post Scriptum (Post Scriptum) (1970-1974) // National corpus of Russian language URL: http://WwW. ruscorpora.ru. (Accessed: 18.07.2018). (In Russian).

28. Shukshin V. Cherednichenko i cirk (Cherednichenko and the Circus) (1970-1974) // National corpus of Russian language URL: http://www. ruscorpora.ru. (Accessed: 18.07.2018). (In Russian). 